Article

\title{
Fish Oil Enriched Intravenous Lipid Emulsions Reduce Triglyceride Levels in Non-Critically Ill Patients with TPN and Type 2 Diabetes. A Post-Hoc Analysis of the INSUPAR Study
}

Jose Abuín-Fernández 1,2 ${ }^{\mathbb{D}}$, María José Tapia-Guerrero ${ }^{1} \mathbb{D}$, Rafael López-Urdiales ${ }^{3}$, Sandra Herranz-Antolín ${ }^{4}$, Jose Manuel García-Almeida ${ }^{5}$, Katherine García-Malpartida ${ }^{6}$, Mercedes Ferrer-Gómez ${ }^{7}$, Emilia Cancer-Minchot ${ }^{8}$, Luis Miguel Luengo-Pérez ${ }^{9}$, Julia Álvarez-Hernández ${ }^{10}$, Carmen Aragón Valera ${ }^{11}$, Julia Ocón-Bretón ${ }^{12}$, Álvaro García-Manzanares ${ }^{13}$, Irene Bretón-Lesmes ${ }^{14}$, Pilar Serrano-Aguayo ${ }^{15}$, Natalia Pérez-Ferre ${ }^{16}$ (D), Juan José López-Gómez ${ }^{17}$ (D), Josefina Olivares-Alcolea ${ }^{18}$, Carmen Arraiza-Irigoyen ${ }^{19}$, Cristina Tejera-Pérez ${ }^{20}$, Jorge Daniel Martínez-González ${ }^{21}$, Ana Urioste-Fondo ${ }^{22}$, Ángel Luis Abad-González ${ }^{23}$, María José Molina-Puerta ${ }^{24}$, Ana Zugasti-Murillo ${ }^{25}$, Juan Parra-Barona ${ }^{26}$, Irela López-Cobo ${ }^{27}$ and Gabriel Olveira ${ }^{1,2,28, * \text { (D) }}$

1 Unidad de Gestión Clínica de Endocrinología y Nutrición, Hospital Regional Universitario de Málaga-Instituto de Investigación Biomédica de Málaga (IBIMA), 29010 Málaga, Spain; jose.abuin.fdez@gmail.com (J.A.-F.); mjtapiague@gmail.com (M.J.T.-G.)

2 Departmento de Medicina y Dermatología, Universidad de Málaga, 29071 Málaga, Spain

3 Servicio de Endocrinología y Nutrición, Hospital Universitari de Bellvitge, 08907 L'Hospitalet de Llobregat (Barcelona), Spain; rlurdiales@gmail.com

4 Servicio de Endocrinología y Nutrición, Hospital Universitario de Guadalajara, 19002 Guadalajara, Spain; herranzantolin@yahoo.es

5 Servicio de Endocrinología y Nutrición, Hospital Universitario Virgen de la Victoria, 29010 Málaga, Spain; jgarciaalmeida@yahoo.com

6 Servicio de Endocrinología y Nutrición, Hospital Universitario y Politécnico La Fe, 46026 Valencia, Spain; kathe.garciamalpartida@gmail.com

7 Servicio de Endocrinología y Nutrición, Hospital Clínico Universitario Virgen de la Arrixaca, 30120 Murcia, Spain; tofly16@gmail.com

8 Sección de Endocrinología y Nutrición, Hospital Universitario de Fuenlabrada, 28942 Madrid, Spain; emilia.cancer@salud.madrid.org

9 Servicio de Endocrinología y Nutrición, Hospital Universitario de Badajoz, 06080 Badajoz, Spain; luismiluengo@yahoo.es

10 Servicio de Endocrinología y Nutrición, Hospital Universitario Príncipe de Asturias, 28805 Madrid, Spain; julia.alvarez@movistar.es

11 Servicio de Endocrinología y Nutrición, Hospital Universitario Fundación Jiménez Díaz, 28040 Madrid, Spain; caragonva@fjd.es

12 Servicio de Endocrinología y Nutrición, Hospital Universitario Lozano Blesa, 50009 Zaragoza, Spain; mjocon@salud.aragon.es

13 Servicio de Endocrinología y Nutrición, Hospital General La Mancha Centro, 13600 Alcázar de San Juan, Spain; agmanzanares2010@gmail.com

14 Servicio de Endocrinología y Nutrición, Hospital Universitario Gregorio Marañón, 28007 Madrid, Spain; irene.breton@salud.madrid.org

15 Unidad de Endocrinología y Nutrición, Hospital Universitario Virgen del Rocío, 41013 Sevilla, Spain; piagua@gmail.com

16 Servicio de Endocrinología y Nutrición, Hospital Clínico San Carlos, 28040 Madrid, Spain; npferre@salud.madrid.org

17 Servicio de Endocrinología y Nutrición, Hospital Clínico Universitario de Valladolid, 47005 Valladolid, Spain; jjlopez161282@hotmail.com

18 Servicio de Endocrinología y Nutrición, Hospital Universitario Son Llatzer, 07198 Illes Balears, Spain; josefinaolivares@gmail.com 
19 Servicio de Endocrinología y Nutrición, Complejo Hospitalario de Jaén, 23007 Jaén, Spain; mc.arraiza.sspa@juntadeandalucia.es

20 Servicio de Endocrinología y Nutrición, Complejo Hospitalario Universitario de Ferrol, 15045 A Coruña, Spain; cristinatejera.mui@gmail.com

21 Servicio de Endocrinología y Nutrición, Hospital Universitario Severo Ochoa, 28914 Leganés (Madrid), Spain; jdmartinglez@gmail.com

22 Servicio de Endocrinología y Nutrición, Complejo Asistencial Universitario de León, 24071 León, Spain; anaurifon@gmail.com

23 Unidad de Nutrición - Sección de Endocrinología, Hospital General Universitario de Alicante, 03010 Alicante, Spain; angeluis1024@gmail.com

24 Servicio de Endocrinología y Nutrición, Hospital Universitario Reina Sofía, 14004 Córdoba, Spain; cmmerinomjmolina@hotmail.com

25 Servicio de Endocrinología y Nutrición, Complejo Hospitalario de Navarra, 31008 Navarra, Spain; azugas@hotmail.com

26 Servicio de Endocrinología y Nutrición, Hospital de Mérida, 06800 Badajoz, Spain; juanparrabarona@gmail.com

27 Servicio de Endocrinología y Nutrición, Hospital de Sant Joan Despí Moisès Broggi, 08970 Barcelona, Spain; irela.lopez@sanitatintegral.org

28 CIBERDEM (CB07/08/0019), Instituto de Salud Carlos III, 28029 Madrid, Spain

* Correspondence: gabrielm.olveira.sspa@juntadeandalucia.es

Received: 9 May 2020; Accepted: 25 May 2020; Published: 27 May 2020

check for updates

Abstract: There are no studies that have specifically assessed the role of intravenous lipid emulsions (ILE) enriched with fish oil in people with diabetes receiving total parenteral nutrition (TPN). The objective of this study was to assess the metabolic control (glycemic and lipid) and in-hospital complications that occurred in non-critically ill inpatients with TPN and type 2 diabetes with regard to the use of fish oil emulsions compared with other ILEs. We performed a post-hoc analysis of the Insulin in Parenteral Nutrition (INSUPAR) trial that included patients who started with TPN for any cause and that would predictably continue with TPN for at least five days. The study included 161 patients who started with TPN for any cause. There were 80 patients (49.7\%) on fish oil enriched ILEs and 81 patients $(50.3 \%)$ on other ILEs. We found significant decreases in triglyceride levels in the fish oil group compared to the other patients. We did not find any differences in glucose metabolic control: mean capillary glucose, glycemic variability, and insulin dose, except in the number of mild hypoglycemic events that was significantly higher in the fish oil group. We did not observe any differences in other metabolic, liver or infectious complications, in-hospital length of stay or mortality.

Keywords: parenteral nutrition; type 2 diabetes mellitus; polyunsaturated fatty acids; omega 3; hospital

\section{Introduction}

Although enteral nutrition is the first option in patients that require nutritional support, total parenteral nutrition is a more appropriate technique to reduce complications and mortality in malnourished patients or in those at risk of being malnourished and who cannot use their digestive tract [1].

Lipid emulsions containing fish oil are rich in n-3 polyunsaturated fatty acids (PUFAs) such as docosahexaenoic acid (DHA) and eicosapentaenoic acid (EPA), which exhibit anti-inflammatory, immunomodulatory, and antioxidative properties in preclinical models. In recent years the evidence to support the use of intravenous lipid emulsions (ILEs) enriched with fish oil has grown increasingly [2-4], showing that they could lower triglyceride concentrations, inflammatory markers, and liver function enzymes, and improve morbidity (risk of infection and sepsis and length of stay) and even 
mortality outcomes in hospitalized patients especially in post-surgical and oncology patients [5-8], when compared with ILEs based on soybean oil.

The European Society of Parenteral and Enteral Nutrition (ESPEN) Expert Group supports the use of olive oil and fish oil (FO) in nutrition support in surgical and non-surgical intensive care unit (ICU) patients, but considers that further research is required to provide a more robust evidence base [9].

It has been reported that n-3 PUFA status is inversely associated with type 2 diabetes and its oral supplementation could reduce insulin resistance, especially in women [10], and could prevent the onset of diabetes [11]. In animal models, intravenously infused n-3 PUFA preserves insulin signaling and glucose uptake compared to the infusion of n-6 PUFA [12].

In people with type 2 diabetes, fish oil supplementation lowers triglycerides but it does not seem to have any statistically significant effect on glycemic control [13].

Currently, there are no specific studies in people with diabetes receiving parenteral nutrition that have assessed the role of emulsions enriched with n-3 PUFA with regard to glycemic and lipid control, nor regarding possible complications.

In the INSUPAR trial, previously published by our group, we assessed two insulin regimens in adult inpatients with type 2 diabetes in a non-critical setting with indication for total parenteral nutrition (TPN; subcutaneously administered glargine insulin vs. regular insulin inside the TPN bag) [14]. Of the 161 patients assessed, $80(49.7 \%)$ received TPN with fish oil enriched emulsions and 81 other ILEs. As this was a clinical trial, we could assess the effect of n-3 PUFA enriched ILEs with regard to other emulsions. Our hypothesis was that enriched n-3 PUFA ILEs could modulate glycemic control and reduce hypertriglyceridemia and complications in these patients.

Therefore, the objective of this post-hoc analysis of the INSUPAR trial was to assess the metabolic control and in-hospital complications that occurred in non-critically ill inpatients with TPN and type 2 diabetes with regard to the use of enriched n-3 PUFA emulsions compared with the other ILEs.

\section{Research Design and Methods}

The results were extracted from the INSUPAR trial [14] (complete details available in the main article). The study included $>18$ years non-critically ill type 2 diabetes in-hospital patients who started with TPN (considering that it provides more than $70 \%$ of the estimated total energy expenditure) for any cause and that would predictably continue with TPN for at least five days. All TPN were infused by central line (ClinicalTrials.gov NCT02706119 and EudraCT 2015-003954-42).

Patients were considered to have diabetes as assessed according to the international criteria [15]. Blood glucose levels were obtained from capillary and the same glucose meter was provided (Freestyle Optium; Abbott Diabetes Care Inc, Witney, Oxon, UK) to every center. Measurements were made four times a day. Optimum blood glucose levels were between 100 and $140 \mathrm{mg} / \mathrm{dL}$. Blood glucose measurements were performed until the patient discontinued TPN or up to 15 days at most. We continued to monitor capillary glucose on days 1 and 2 after TPN was stopped.

Hypoglycemia was defined as blood glucose $\leq 70 \mathrm{mg} / \mathrm{dL}$ [16]. Glycemic variability (GV) was measured by standard deviation and variation coefficient of capillary glucose.

The following baseline data were recorded: demographic variables, treatment modality, diagnosis on admission, prior comorbidity (Charlson Comorbidity Index [17]), anthropometric data (body mass index (BMI)), nutritional assessment by subjective global assessment (SGA), type 2 diabetes related parameters, TPN characteristics, and concomitant prescription of drugs that could induce hyperglycemia.

\subsection{Analytical Assessment during TPN Infusion}

Analytical follow-up was made according to common clinical practice in each center, but at least a blood count, coagulation, and biochemistry were made on days 1 and 5 since the beginning of TPN, and the day before stopping it. A fasting blood sample was drawn to measure: the glycated hemoglobin (following the international recommendations for standardization of the HbA1c measurement [18]), 
plasma blood glucose, C-reactive protein (CRP), triglycerides, cholesterol, creatinine, urea, electrolytes, and blood liver function at the laboratories of each hospital (with an autoanalyzer).

\subsection{Metabolic and Liver Complications}

Urea increase was considered if the previous value was normal and then increased above $80 \mathrm{mg} / \mathrm{dL}$ after the beginning of TPN. Creatinine increase was considered if the previous value was normal and then increased above $1.3 \mathrm{mg} / \mathrm{dL}$ after the beginning of TPN. Any analytical value above or below the following normal ranges was considered a complication: hypertriglyceridemia ( $>400 \mathrm{mg} / \mathrm{dL}$ ) [4], hypernatremia ( $>150 \mathrm{mEq} / \mathrm{L})$, hyponatremia $(<135 \mathrm{mEq} / \mathrm{L})$, hypokalemia $(<3 \mathrm{mEq} / \mathrm{L})$, hypomagnesemia $(<1.2 \mathrm{mg} / \mathrm{dL})$, hypophosphatemia $(<2 \mathrm{mg} / \mathrm{dL})$, hyperchloremia $(>120 \mathrm{mEq} / \mathrm{L})$, and hypocalcemia (with corrected Calcium for Albumin; $<8 \mathrm{mg} / \mathrm{dL}$ ).

Liver function was considered altered when liver enzymes increased above twice the upper normal limit in at least two of its parameters (being previously normal): Aspartate Transaminase (AST), Alanine Transaminase (ALT), Gamma-Glutamyltransferase (GGT), and Alkaline Phosphatase after the beginning of TPN.

Other complications were evaluated from the beginning of TPN to the discharge of the patients, not only during TPN infusion:

- Infectious non-catheter and catheter related bloodstream infections; they were identified as an elevated white blood cell count in addition to one or more of the following: positive blood cultures, chest $x$-ray suggestive of pneumonia, positive urine culture, postoperative wound infection, and use of antibiotics.

- Length of stay.

- In-hospital mortality.

\subsection{Statistical Analysis}

Data analysis was performed using SPSS version 22.0 (Armonk, NY, USA) [19]. The Kolmogorov-Smirnov test was used to assess whether the variables were normally distributed or not. The hypothesis contrast between proportions was done using the $\chi^{2}$ test with Fisher's exact test, when necessary. Hypothesis contrast for continuous variables between groups used the $t$-test for variables that followed a normal distribution, and a non-parametric test (Mann-Whitney) for variables that did not conform to normal. In the case that significant differences between groups were found in any of the baseline characteristics, we used a general lineal model adjusted by these covariates (sex and TPN duration).

Variables tested repeatedly over time (glucose, CRP, triglycerides, cholesterol, and blood liver function) were also analyzed using repeated measures multiple analysis of variance according to time and group of ILEs.

For all the calculations, significance was set at $p<0.05$ for two tails.

\section{Results}

\section{Sample}

A total of 161 patients were included in the INSUPAR study (80 in the Regular Insulin group and 81 in the Glargine group). Of them, 80 patients (49.7\%) were on ILEs enriched with n-3 PUFA and 81 patients $(50.3 \%)$ on other ILEs, where $49(27.5 \%)$ received a mixture of medium and long chain triglycerides (MCT/LCT; Lipofundina MCT/LCT 20\%; B. Braun Medical, Rubí, Barcelona, Spain), $29(16.3 \%)$ based on olive oil (Clinoleic 20\%; Baxter, Ribarroja del Turia, Valencia, Spain), and three $(1.7 \%)$ based on pure soybean oil (Intralipid; Fresenius Kabi España, Barcelona, Spain. Of the 80 patients with n-3 PUFA, 49 (61.3\%) of them were with Smoflipid (Fresenius Kabi AB, Uppsala, Sweden) and 
$31(38.7 \%)$ of them were on Lipoplus (B. Braun Melsungen AG, Melsungen, Germany). The mean daily $\mathrm{n}-3$ PUFA intake was $4.34 \pm 1.19 \mathrm{~g}$ and $0.067 \pm 0.0201 \mathrm{~g} / \mathrm{kg}$.

We did not find any differences in the baseline characteristics between both groups other than a higher percentage of men and higher duration of TPN in the n-3 PUFA group (Table 1).

We did not find any differences in glucose metabolic control (mean capillary glucose, glycemic variability and insulin dose) except for the number of mild hypoglycemic events being significantly higher in the n-3 PUFA group (Table 2). We did not observe any differences in other metabolic, liver or infectious complications, in-hospital length of stay, or mortality. We observed a significant decrease in triglyceride levels in the n-3 PUFA group on day 5 and the last day of TPN compared to day 1 and significant differences between groups (Table 3 and Figure 1).

Table 1. Baseline characteristics.

\begin{tabular}{|c|c|c|c|}
\hline Variable & $\begin{array}{c}\text { Other ILEs } \\
n=81(50.3 \%)\end{array}$ & $\begin{array}{c}\text { n-3 PUFA } \\
n=80(49.7 \%)\end{array}$ & $p$-Value \\
\hline \multicolumn{4}{|l|}{ Gender } \\
\hline Men, $n(\%)$ & $47(58.0 \%)$ & $63(78.8 \%)$ & \multirow{2}{*}{0.004} \\
\hline Women, $n(\%)$ & $34(42.0 \%)$ & $17(21.2 \%)$ & \\
\hline Age (years) & $71.6 \pm 10.3$ & $70.4 \pm 9.5$ & 0.451 \\
\hline \multicolumn{4}{|l|}{ Group of treatment } \\
\hline Regular insulin, $n(\%)$ & $40(49.4 \%)$ & $40(50.0 \%)$ & \multirow{2}{*}{0.938} \\
\hline Glargine insulin, $n(\%)$ & $41(50.6 \%)$ & $40(50.0 \%)$ & \\
\hline \multicolumn{4}{|l|}{ Subjective global assessment } \\
\hline Well nourished, $n(\%)$ & $28(34.6 \%)$ & $24(30.0 \%)$ & \multirow{3}{*}{0.549} \\
\hline Moderate malnutrition, $n(\%)$ & $32(39.5 \%)$ & $29(36.3 \%)$ & \\
\hline Severe malnutrition, $n(\%)$ & $21(25.9 \%)$ & $27(33.7 \%)$ & \\
\hline \multicolumn{4}{|l|}{ Blood test parameters } \\
\hline Creatinine (mg/dL) & $0.84 \pm 0.24$ & $0.77 \pm 0.25$ & 0.089 \\
\hline Albumin (mg/dL) & $2.57 \pm 0.52$ & $2.47 \pm 0.57$ & 0.219 \\
\hline $\mathrm{C}$ reactive protein $(\mathrm{mg} / \mathrm{dL})$ & $112.3 \pm 103.6$ & $90.2 \pm 90.9$ & 0.169 \\
\hline \multicolumn{4}{|l|}{ Reason for admission } \\
\hline Surgical, $n(\%)$ & $41(50.6 \%)$ & $43(53.8 \%)$ & \multirow{3}{*}{0.242} \\
\hline Oncohematological, $n(\%)$ & $22(27.2 \%)$ & $27(33.7 \%)$ & \\
\hline Medical, $n(\%)$ & $18(22.2 \%)$ & $10(12.5 \%)$ & \\
\hline Charlson comorbidity index & $6.5 \pm 2.9$ & $7.1 \pm 2.9$ & 0.188 \\
\hline \multicolumn{4}{|l|}{ Type 2 diabetes mellitus } \\
\hline Duration of type 2 diabetes mellitus (years) & $11.0 \pm 8.5$ & $11.3 \pm 7.3$ & 0.840 \\
\hline Diabetes with end-organ damage, $n(\%)$ & $10(12.3 \%)$ & $15(18.8 \%)$ & 0.262 \\
\hline Patients with insulin prior to the admission, $n(\%)$ & $20(24.7 \%)$ & $26(32.5 \%)$ & 0.230 \\
\hline Insulin units prior to the admission (IU/kg/day) & $0.36 \pm 0.23$ & $0.55 \pm 0.34$ & 0.075 \\
\hline $\operatorname{HbA1c}(\%)$ & $6.60 \pm 1.0$ & $6.6 \pm 1.2$ & 0.912 \\
\hline Plasma glucose (mg/dL) & $190.3 \pm 64.3$ & $184.3 \pm 81.5$ & 0.604 \\
\hline Real weight $(\mathrm{kg})$ & $71.16 \pm 17.33$ & $74.14 \pm 15.73$ & 0.255 \\
\hline BMI $\left(\mathrm{kg} / \mathrm{m}^{2}\right)$ & $27.14 \pm 5.50$ & $27.22 \pm 5.88$ & 0.919 \\
\hline$<18.5 \mathrm{~kg} / \mathrm{m}^{2}$ & $1(1.2 \%)$ & $3(3.7 \%)$ & \multirow{4}{*}{0.724} \\
\hline $18.5-25.0 \mathrm{~kg} / \mathrm{m}^{2}$ & $30(37.0 \%)$ & $27(33.8 \%)$ & \\
\hline $25.0-30.0 \mathrm{~kg} / \mathrm{m}^{2}$ & $32(39.5 \%)$ & $30(37.5 \%)$ & \\
\hline$>30.0 \mathrm{~kg} / \mathrm{m}^{2}$ & $18(22.2 \%)$ & $20(25.0 \%)$ & \\
\hline Total energy expenditure (kcal) & $1599.0 \pm 248.7$ & $1636.5 \pm 210.0$ & 0.303 \\
\hline Any drug induces hyperglycemia, $n(\%)$ & $17(21.0 \%)$ & $20(25.0 \%)$ & 0.545 \\
\hline TPN duration (days) & $8.6 \pm 4.3$ & $11.6 \pm 8.8$ & 0.007 \\
\hline
\end{tabular}

BMI, body mass index; HbA1c, glycated hemoglobin; ILEs, intravenous lipid emulsions; PUFA, polyunsaturated fatty acids; TPN, total parenteral nutrition. Bold $p$-values indicate statistical significance. 
Table 2. Glycemic-related variables.

\begin{tabular}{|c|c|c|c|}
\hline & $\begin{array}{c}\text { Other ILEs } \\
n=81(50.3 \%)\end{array}$ & $\begin{array}{c}\text { n-3 PUFA } \\
n=80(49.7 \%)\end{array}$ & $p$-Value * \\
\hline \multicolumn{4}{|l|}{ Insulin } \\
\hline Mean total daily insulin (IU/kg) & $45.7 \pm 26.1$ & $47.5 \pm 26.8$ & 0.662 \\
\hline $\begin{array}{l}\text { Mean total daily insulin/ } 10 \mathrm{~g} \text { of carbohydrates in } \\
\text { TPN (IU) }\end{array}$ & $2.5 \pm 1.2$ & $2.5 \pm 1.3$ & 0.894 \\
\hline \multicolumn{4}{|l|}{ Mean capillary glucose } \\
\hline $08: 00 \mathrm{~h}(\mathrm{mg} / \mathrm{dL})$ & $169.1 \pm 41.3$ & $163.6 \pm 40.4$ & 0.398 \\
\hline $13: 00 \mathrm{~h}(\mathrm{mg} / \mathrm{dL})$ & $176 \pm 42.6$ & $172.1 \pm 42.3$ & 0.560 \\
\hline $20: 00 \mathrm{~h}(\mathrm{mg} / \mathrm{dL})$ & $174.1 \pm 44.5$ & $163 \pm 38.6$ & 0.100 \\
\hline $00: 00 \mathrm{~h}(\mathrm{mg} / \mathrm{dL})$ & $164.7 \pm 44.6$ & $159.1 \pm 42.3$ & 0.446 \\
\hline During TPN $(\mathrm{mg} / \mathrm{dL})$ & $172.4 \pm 40.9$ & $165.4 \pm 38.6$ & 0.269 \\
\hline $\begin{array}{l}\text { Mean post-TPN capillary blood glucose } 48 \mathrm{~h} \\
(\mathrm{mg} / \mathrm{dL})\end{array}$ & $156 \pm 49.1$ & $145.5 \pm 40.5$ & 0.206 \\
\hline \multicolumn{4}{|l|}{ Hypoglycemic variables } \\
\hline Number of capillary glucose $\leq 70 \mathrm{mg} / \mathrm{dL}, n(\%)$ & $0.18 \pm 0.61$ & $0.55 \pm 1.17$ & 0.012 \\
\hline Number of capillary glucose $<54 \mathrm{mg} / \mathrm{dL}, n(\%)$ & $0.04 \pm 0.19$ & $0.06 \pm 0.24$ & 0.471 \\
\hline \multicolumn{4}{|l|}{ Capillary glucose variability } \\
\hline Standard deviation of capillary glucose $(\mathrm{mg} / \mathrm{dL})$ & $41.3 \pm 18.7$ & $42.6 \pm 16.5$ & 0.634 \\
\hline Variation coefficient of capillary glucose (\%) & $24 \pm 9.2$ & $25.9 \pm 9.2$ & 0.187 \\
\hline
\end{tabular}

* Adjusted for gender and duration of TPN. Bold $p$-values indicate statistical significance.

Table 3. Complications.

\begin{tabular}{|c|c|c|c|c|c|c|}
\hline & & $\begin{array}{c}\text { Other ILEs } \\
n=81(50.3 \%)\end{array}$ & & $\begin{array}{c}\text { n-3 PUFA } \\
n=80(49.7 \%)\end{array}$ & $p$-Value * & \\
\hline \multicolumn{7}{|c|}{ Metabolic and liver complications } \\
\hline \multicolumn{2}{|c|}{ Hypertriglyceridemia, $n(\%)$} & $6(7.4 \%)$ & & $4(5.0 \%)$ & 0.527 & \\
\hline \multicolumn{2}{|c|}{ Hypernatremia, $n(\%)$} & $1(1.2 \%)$ & & $5(6.3 \%)$ & 0.093 & \\
\hline \multicolumn{2}{|c|}{ Hyponatremia, $n(\%)$} & $2(2.5 \%)$ & & $7(8.8)$ & 0.083 & \\
\hline \multicolumn{2}{|c|}{ Hypokalemia, $n(\%)$} & $7(8.6 \%)$ & & $8(10.0 \%)$ & 0.767 & \\
\hline \multicolumn{2}{|c|}{ Hypophosphatemia, $n(\%)$} & $8(9.9 \%)$ & & $11(13.8 \%)$ & 0.446 & \\
\hline \multicolumn{2}{|c|}{ Hypocalcemia (with corrected calcium), $n$ (\%) } & $2(2.5 \%)$ & & $2(2.5 \%)$ & 0.980 & \\
\hline \multicolumn{2}{|c|}{ Increased creatinine, $n(\%)$} & $5(6.2 \%)$ & & $4(5.0 \%)$ & 0.732 & \\
\hline \multicolumn{2}{|c|}{ Increased urea, $n(\%)$} & $5(6.2 \%)$ & & $7(8.8 \%)$ & 0.533 & \\
\hline \multicolumn{2}{|c|}{ Liver complications, $n(\%)$} & $5(6.2 \%)$ & & $7(8.8 \%)$ & 0.534 & \\
\hline \multicolumn{7}{|c|}{ Infectious and other complications } \\
\hline \multicolumn{2}{|c|}{ Central line-associated bloodstream infections, $n(\%)$} & $6(7.4 \%)$ & & $11(13.8 \%)$ & 0.190 & \\
\hline \multicolumn{2}{|c|}{ Sepsis, $n(\%)$} & $4(4.9 \%)$ & & $6(7.5 \%)$ & 0.501 & \\
\hline \multicolumn{2}{|c|}{ Pneumonia, $n(\%)$} & $4(4.9 \%)$ & & $2(2.5 \%)$ & 0.414 & \\
\hline \multicolumn{2}{|c|}{ Surgical site infection, $n(\%)$} & $5(6.2 \%)$ & & $8(10.0 \%)$ & 0.360 & \\
\hline \multicolumn{2}{|c|}{ Urinary tract infection, $n(\%)$} & $3(3.7 \%)$ & & $2(2.5 \%)$ & 0.660 & \\
\hline \multicolumn{2}{|c|}{ Mortality, $n(\%)$} & $10(12.3 \%)$ & & $14(17.5 \%)$ & 0.359 & \\
\hline \multicolumn{2}{|c|}{ Length of hospital stay (days) } & $28.7 \pm 20.0$ & & $32.2 \pm 27.5$ & 0.367 & \\
\hline \multirow[t]{2}{*}{ Blood test results } & Days & & Days & & & $\begin{array}{c}\text { Analysis of } \\
\text { variance }\end{array}$ \\
\hline & $1(n=79)$ & $194.8 \pm 86.8$ & $1(n=79)$ & $182.5 \pm 93.9$ & 0.663 & \\
\hline \multirow[t]{3}{*}{ Triglycerides $(\mathrm{mg} / \mathrm{dL})^{\$}$} & $5(n=70)$ & $220.3 \pm 134.8$ & $5(n=68)$ & $147.5 \pm 72.6^{\&}$ & 0.052 & 0.028 \\
\hline & Last $(n=19)$ & $217.9 \pm 117.1$ & Last $(n=28)$ & $143.1 \pm 63.7 \&$ & 0.024 & \\
\hline & $1(n=79)$ & $115.9 \pm 48.3$ & $1(n=79)$ & $117.7 \pm 51.2$ & 0.825 & \\
\hline \multirow[t]{3}{*}{ Total cholesterol (mg/dL) } & $5(n=72)$ & $123.4 \pm 37.1$ & $5(n=65)$ & $114.7 \pm 33.8$ & 0.156 & 0.220 \\
\hline & Last $(n=19)$ & $135.2 \pm 44.9$ & Last $(n=26)$ & $119.9 \pm 35.3$ & 0.206 & \\
\hline & $1(n=50)$ & $23.6 \pm 12.2$ & $1(n=51)$ & $23.1 \pm 11.4$ & 0.831 & \\
\hline \multirow[t]{3}{*}{ HDL cholesterol (mg/dL) } & $5(n=45)$ & $21.9 \pm 8.9$ & $5(n=43)$ & $20.1 \pm 9.4$ & 0.366 & 0.401 \\
\hline & Last $(n=7)$ & $18.9 \pm 6.5$ & Last $(n=19)$ & $19.2 \pm 8.6$ & 0.934 & \\
\hline & $1(n=49)$ & $50.1 \pm 26.6$ & $1(n=47)$ & $58.6 \pm 42.4$ & 0.246 & \\
\hline \multirow[t]{3}{*}{ LDL cholesterol (mg/dL) } & $5(n=44)$ & $61.8 \pm 30.9$ & $5(n=40)$ & $58.3 \pm 28.7$ & 0.586 & 0.770 \\
\hline & Last $(n=6)$ & $73.2 \pm 40.4$ & Last $(n=18)$ & $69.4 \pm 32.1$ & 0.817 & \\
\hline & $1(n=78)$ & $29.1 \pm 33.1$ & $1(n=78)$ & $29.7 \pm 36.5$ & 0.936 & \\
\hline \multirow[t]{2}{*}{ Aspartate transaminase $(\mathrm{U} / \mathrm{L})$} & $5(n=67)$ & $35.0 \pm 37.2$ & $5(n=59)$ & $35.9 \pm 38.0$ & 0.897 & 0.797 \\
\hline & Last $(n=20)$ & $32.0 \pm 27.4$ & Last $(n=32)$ & $31.3 \pm 35.9$ & 0.939 & \\
\hline
\end{tabular}


Table 3. Cont

\begin{tabular}{|c|c|c|c|c|c|c|}
\hline & & $\begin{array}{c}\text { Other ILEs } \\
n=81(50.3 \%)\end{array}$ & & $\begin{array}{c}\text { n-3 PUFA } \\
n=80(49.7 \%)\end{array}$ & $p$-Value * & \\
\hline \multirow{3}{*}{ Alanine aminotransferase (U/L) } & $1(n=78)$ & $30.6 \pm 32.9$ & $1(n=78)$ & $29.9 \pm 33.4$ & 0.904 & \multirow{3}{*}{0.319} \\
\hline & $5(n=72)$ & $38.8 \pm 49.2$ & $5(n=68)$ & $32.4 \pm 30.6$ & 0.363 & \\
\hline & Last $(n=21)$ & $35.2 \pm 44.9$ & Last $(\mathrm{N}=34)$ & $30.4 \pm 26.7$ & 0.624 & \\
\hline \multirow{3}{*}{ Gamma glutamyl transferase (U/L) } & $1(n=78)$ & $98.2 \pm 131.4$ & $1(n=78)$ & $151.5 \pm 183.3$ & 0.057 & \multirow{3}{*}{0.303} \\
\hline & $5(n=64)$ & $177.2 \pm 155.7$ & $5(n=58)$ & $199.4 \pm 185.2$ & 0.474 & \\
\hline & Last $(n=19)$ & $171.4 \pm 155.0$ & Last $(n=28)$ & $211.6 \pm 205.4$ & 0.472 & \\
\hline \multirow{3}{*}{ Alcaline phosphatase (U/L) } & $1(n=78)$ & $115.8 \pm 111.6$ & $1(n=78)$ & $139.8 \pm 197.9$ & 0.339 & \multirow{3}{*}{0.549} \\
\hline & $5(n=68)$ & $151.3 \pm 125.3$ & $5(n=66)$ & $154.2 \pm 186.9$ & 0.918 & \\
\hline & Last $(n=20)$ & $121.0 \pm 60.0$ & Last $(n=32)$ & $166.0 \pm 160.0$ & 0.234 & \\
\hline \multirow{3}{*}{$\mathrm{C}$ reactive protein $(\mathrm{mg} / \mathrm{L})$} & $1(n=71)$ & $112.3 \pm 103.6$ & $1(n=77)$ & $90.2 \pm 90.9$ & 0.169 & \multirow{3}{*}{0.320} \\
\hline & $5(n=66)$ & $68.7 \pm 77.9$ & $5(n=68)$ & $65.3 \pm 79.6$ & 0.805 & \\
\hline & Last $(n=15)$ & $58.4 \pm 81.4$ & Last $(n=29)$ & $56.2 \pm 48.6$ & 0.913 & \\
\hline
\end{tabular}

HDL, high density lipoprotein; LDL, low density lipoprotein; * $p$-value between groups of ILEs adjusted for gender and TPN duration. ${ }^{\$}$ Differences between groups by repeated measures multiple analysis of variance according to time (days 1,5, and 15) and group of ILEs. ${ }^{\&} p<0.01$ in the n-3 PUFA group between day 1 and 5 and between day 1 and the last day. Bold $p$-values indicate statistical significance.

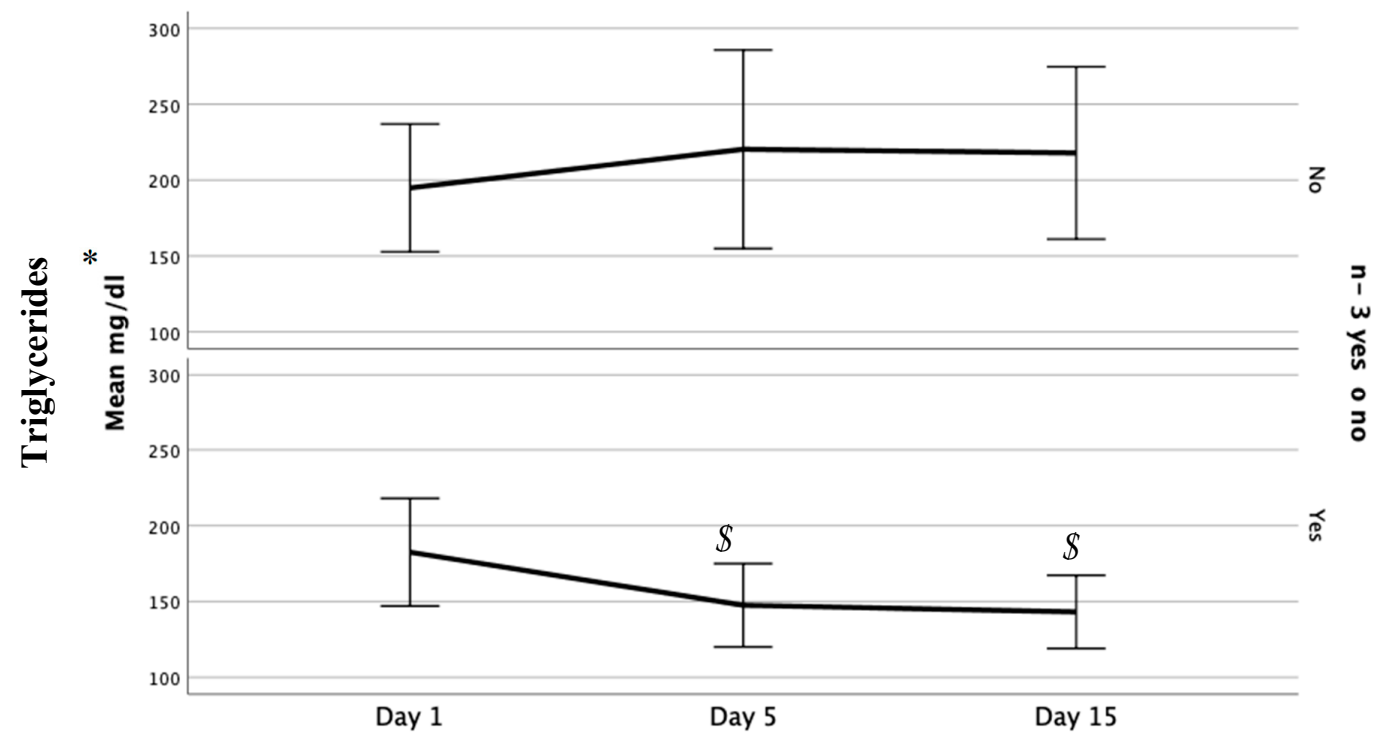

Figure 1. Evolution of Triglyceride levels by group. ${ }^{*}$ Differences between groups by repeated measures multiple analysis of variance; $\$ p<0.01$ in the $n-3$ polyunsaturated fatty acids (PUFA) group between day 1 and 5 and between day 1 and the last day.

\section{Discussion}

In this study, we observed that in non-critically ill patients with type 2 diabetes mellitus (T2DM) who received TPN with n-3 PUFA enriched ILEs (compared to other ILEs), triglyceride levels were significantly reduced and presented a higher number of mild hypoglycemia events. On the other hand, we did not find any differences in other parameters of glycemic or lipid metabolic control, liver or infectious complications, hospital length of stay or mortality.

Lipid emulsions are used in parenteral nutrition $(\mathrm{PN})$ with the objective of supplying an energy-dense source of calories, reducing the glycemic load, supplying essential fatty acids, and lowering osmolarity [8]. The first generation of lipid emulsions was based on soybean oil and contained high concentrations of n-6 PUFA that could promote inflammation [3]. Fish oil contains $\omega-3$ PUFAs (docosahexaenoic acid [DHA] and eicosapentaenoic acid [EPA]) that incorporate into cell membranes influencing various transcription factors modifying the expression of genes involved in many biological processes which include metabolism, immune function, and inflammation [3]. ILEs based on fish oil have been shown to have anti-inflammatory and immunomodulatory effects [5]. 


\subsection{Lipid Control and Liver Enzymes}

Oral fish oil supplementation has been shown to produce a clinically significant, dose-dependent reduction in fasting blood triglycerides and normalize serum lipid concentrations, including high-density lipoproteins (HDL) and low-density lipoproteins (LDL), in patients with diabetes mellitus [2]. In patients with PN it is not uncommon to experience increases in serum triglyceride concentrations and hypertriglyceridemia correlated with hepatic steatosis, which can contribute to liver damage. In this regard, ILEs based on fish oil may be protective against rapid increases in serum triglycerides, compared with other formulas such as those based on MCT/LCT, although the evidence is not conclusive $[5,20]$. In our study we did not observe any differences in the percentage of patients that developed hypertriglyceridemia (levels above $400 \mathrm{mg} / \mathrm{dL}$ ) which was, in any case, low in both groups (5\% in the n-3 PUFA group and $7.4 \%$ in the other group); nonetheless, we observed significant reductions of levels of serum triglycerides in the n-3 PUFA group.

Lipid composition of TPN could also play a significant role in liver enzyme alteration associated with PN, and n-3 PUFA ILEs have been shown to minimize this disturbance in hospitalized adult patients by reducing liver complications [21,22]. The administration of high doses of intravenous lipids, that are high in n-6 PUFAs and phytosterols (like the ones based on soybean oils), can contribute to the development of parenteral nutrition-associated liver disease [23]. ILEs based exclusively on fish oil reduce plasmatic phytosterol levels and are associated with an improvement in liver profile [24,25]. In our study, regarding analytical data, we did not find any differences in liver profile, neither in the percentage of patients with an increase in liver enzymes nor in the number of patients with liver complications. This could be because the use of ILEs based on pure soybean oil was very low (only three patients, $1.7 \%$ of the sample) in our sample. Therefore, even the rest of the formulas used in our study (MCT/LCT, olive oil, and fish oil emulsions) contain variable quantities of n-6 PUFA (but always less than pure soybean oils), and these ILEs could have advantages due to the reduced accumulation of phytosterols and because of the mitigation of the proinflammatory effect of n-6 PUFA, as well as potentiate positive effects of other lipid sources [26].

\subsection{Complications}

Several studies have also shown a significant decrease in hospital stay, especially in ICU surgical patients $[3,5,7,9,27]$ and in infectious complications $[2,28,29]$ when using ILEs based on fish oil compared mainly with ILEs based on pure soybean oil or MCT/LCT emulsions. A reduction of infectious complications is seen with the doses that are usually applied in clinical practice [3] and is supported by the observations that using these fish oil containing ILEs can decrease the blood concentrations or ex-vivo production of proinflammatory eicosanoids and cytokines $[3,5]$. In our sample we administered similar doses to those used in other studies [3], but we did not find any differences in these parameters and also $C$ reactive protein levels decreased similarly in both groups.

A possible cause of the lack of differences compared to other studies could be a limited sample but also due to the fact that we were comparing enriched n-3 PUFA emulsions vs. other ILEs that are not based on n-6 PUFA as the only source and thus these already have an improved composition (50\% MCT and olive oil ILEs) [3,8].

\subsection{Glycemic Control}

With regard to glycemic control, it was also similar when comparing both groups with regard to mean capillary blood glucose, insulin dose, and glycemic variability; however, we observed a small but significantly higher number of mild hypoglycemia events in the n-3 PUFA group. This could be explained due to a higher insulin sensitivity in patients using n-3 PUFA [10]. Besides this, patients with n-3 PUFA ILEs had a non-statistically significant tendency to present a higher proportion of patients with T2DM with end-organ damage and significantly longer TPN duration, both variables that have been associated with a higher risk of hypoglycemia in T2DM patients [30]. On the other hand, they did 
not have greater glycemic variability differences in the percentage of patients with glargine or regular insulin [30].

\subsection{Limitations and Conclusions}

The main advantages of our study are that it is a prospective multi-center study, with a considerable sample (compared to other studies), and very homogeneous (all of them previously diagnosed with T2DM) and it involves a follow-up of the patients from admission to discharge, not only during TPN infusion. However, the current study is not free from limitations as it is a post-hoc analysis, we only focus on non-critically ill patients with type 2 diabetes mellitus; therefore, we cannot apply these conclusions to other groups of patients. On the other hand, there could be differences regarding the cause of the admission (surgical, oncohematological, or medical) that we have not assessed.

In conclusion, although the results come from a post-hoc analysis of our previous study, we found that in non-critically ill patients with T2DM who received TPN with lipid emulsions enriched with n-3 PUFA, triglyceride levels were significantly reduced and presented a higher number of mild hypoglycemia events without differences in glycemic control and in-hospital complications compared to other lipid emulsions. Future prospective research is needed to examine the effect of n-3 PUFA on patients with diabetes receiving PN.

Author Contributions: G.O. substantially contributed to the conception and design of the study, acquisition, analysis, and interpretation of the data; statistical analysis; and drafting of the manuscript. J.A.-F. contributed to the acquisition, analysis, and interpretation of the data; statistical analysis; revised the article for important intellectual content and drafting of the manuscript. R.L.-U., S.H.-A., J.M.G.-A., K.G.-M., M.F.-G., E.C.-M., L.M.L.-P., J.Á.-H., C.A.V., J.O.-B., Á.G.-M., I.B.-L., P.S.-A., N.P.-F., J.J.L.-G., J.O.-A., C.A.-I., C.T.-P., J.D.M.-G., A.U.-F., Á.L.A.-G., M.J.M.-P., A.Z.-M., J.P.-B., and I.L.-C. contributed to the data acquisition and critical review of the manuscript. M.J.T.-G. substantially contributed to the design of the article; data acquisition; and critical review of the manuscript. G.O. and J.A.-F. are the guarantors of this work and, as such, had full access to all the data in the study and take responsibility for the integrity of the data and the accuracy of the data analysis. All authors have read and agreed to the published version of the manuscript.

Funding: This work was supported by Instituto de Salud Carlos III (ISCIII, co-funded by Fondo Europeo de Desarrollo Regional [FEDER], European Union [EU], “Una manera de hacer Europa”), Ministerio de Ciencia, Innovación y Universidades, Gobierno de España (PI15/01034), and Sociedad Andaluza de Endocrinología Diabetes y Nutritión (SAEDYN) 2016 research project. Centro de Investigación Biomédica en Red (CIBERDEM) is an initiative of the Instituto de Salud Carlos III.

Acknowledgments: We want to thank every patient who participated in the study and every member of the Study Group of Hyperglycemia in Parenteral Nutrition; Nutrition Area of the Spanish Society of Endocrinology and Nutrition (SEEN).

Conflicts of Interest: The authors have no multiplicity of interest to disclose.

\section{References}

1. Weimann, A.; Braga, M.; Carli, F.; Higashiguchi, T.; Hübner, M.; Klek, S.; Laviano, A.; Ljungqvist, O.; Lobo, D.N.; Martindale, R.; et al. ESPEN guideline: Clinical nutrition in surgery. Clin. Nutr. 2017, 36, 623-650. [CrossRef] [PubMed]

2. Klek, S. Omega-3 Fatty Acids in Modern Parenteral Nutrition: A Review of the Current Evidence. J. Clin. Med. 2016, 5, 34. [CrossRef] [PubMed]

3. Calder, P.C. Intravenous Lipid Emulsions to Deliver Bioactive Omega-3 Fatty Acids for Improved Patient Outcomes. Mar. Drugs 2019, 17, 274. [CrossRef] [PubMed]

4. Martindale, R.G.; Berlana, D.; Boullata, J.I.; Cai, W.; Calder, P.C.; Deshpande, G.H.; Evans, D.; Garcia-de-Lorenzo, A.; Goulet, O.J.; Li, A.; et al. Summary of Proceedings and Expert Consensus Statements From the International Summit “Lipids in Parenteral Nutrition". J. Parenter. Enter. Nutr. 2020, 44, S7-S20. [CrossRef] [PubMed]

5. Honeywell, S.; Zelig, R.; Rigassio Radler, D. Impact of Intravenous Lipid Emulsions Containing Fish Oil on Clinical Outcomes in Critically Ill Surgical Patients: A Literature Review. Nutr. Clin. Pract. 2019, 34, 112-122. [CrossRef] [PubMed] 
6. Zhao, Y.; Wang, C. Effect of v-3 polyunsaturated fatty acid-supplemented parenteral nutrition on inflammatory and immune function in postoperative patients with gastrointestinal malignancy A meta-analysis of randomized control trials in China. Medicine 2018, 97. [CrossRef]

7. Lu, C.; Sharma, S.; McIntyre, L.; Rhodes, A.; Evans, L.; Almenawer, S.; Leduc, L.; Angus, D.C.; Alhazzani, W. Omega-3 supplementation in patients with sepsis: A systematic review and meta-analysis of randomized trials. Ann. Intensive Care 2017, 7, 58. [CrossRef] [PubMed]

8. Pradelli, L.; Mayer, K.; Klek, S.; Omar Alsaleh, A.J.; Clark, R.A.C.; Rosenthal, M.D.; Heller, A.R.; Muscaritoli, M. w-3 Fatty-Acid Enriched Parenteral Nutrition in Hospitalized Patients: Systematic Review With Meta-Analysis and Trial Sequential Analysis. J. Parenter. Enter. Nutr. 2020, 44, 44-57. [CrossRef]

9. Calder, P.C.; Adolph, M.; Deutz, N.E.; Grau, T.; Innes, J.K.; Klek, S.; Lev, S.; Mayer, K.; Michael-Titus, A.T.; Pradelli, L.; et al. Lipids in the intensive care unit: Recommendations from the ESPEN Expert Group. Clin. Nutr. 2018, 37, 1-18. [CrossRef]

10. Abbott, K.A.; Burrows, T.L.; Thota, R.N.; Acharya, S.; Garg, M.L. Do v-3 PUFAs affect insulin resistance in a sex-specific manner? A systematic review and meta-analysis of randomized controlled trials. Am. J. Clin. Nutr. 2016, 104, 1470-1484. [CrossRef] [PubMed]

11. Merone, L.; McDermott, R. Nutritional anti-inflammatories in the treatment and prevention of type 2 diabetes mellitus and the metabolic syndrome. Diabetes Res. Clin. Pract. 2017, 127, 238-253. [CrossRef] [PubMed]

12. Lou, P.-H.; Lucchinetti, E.; Hersberger, M.; Clanachan, A.S.; Zaugg, M. Lipid Emulsion Containing High Amounts of n3 Fatty Acids (Omegaven) as Opposed to n6 Fatty Acids (Intralipid) Preserves Insulin Signaling and Glucose Uptake in Perfused Rat Hearts. Anesth. Analg. 2020, 130, 37-48. [CrossRef] [PubMed]

13. Montori, V.M.; Farmer, A.; Wollan, P.C.; Dinneen, S.F. Fish oil supplementation in type 2 diabetes: A quantitative systematic review. Diabetes Care 2000, 23, 1407-1415. [CrossRef] [PubMed]

14. Olveira, G.; Abuín, J.; López, R.; Herranz, S.; García-Almeida, J.M.; García-Malpartida, K.; Ferrer, M.; Cancer, E.; Luengo-Pérez, L.M.; Álvarez, J.; et al. Regular insulin added to total parenteral nutrition vs subcutaneous glargine in non-critically ill diabetic inpatients, a multicenter randomized clinical trial: INSUPAR trial. Clin. Nutr. 2019. [CrossRef]

15. American Diabetes Association. 2. Classification and Diagnosis of Diabetes: Standards of Medical Care in Diabetes-2019. Diabetes Care 2019, 42, S13-S28. [CrossRef]

16. Pasquel, F.J.; Spiegelman, R.; Mccauley, M.; Smiley, D.; Umpierrez, D.; Johnson, R.; Pasquel, F.J.; Spiegelman, R.; McCauley, M.; Smiley, D.; et al. Hyperglycemia during total parenteral nutrition an important marker of poor outcome and mortality in hospitalized patients. Diabetes Care 2010, 33, 739-741. [CrossRef] [PubMed]

17. Charlson, M.E.; Pompei, P.; Ales, K.L.; MacKenzie, C.R. A new method of classifying prognostic comorbidity in longitudinal studies: Development and validation. J. Chronic. Dis. 1987, 40,373-383. [CrossRef]

18. Hanas, R.; John, G.; International HBA1c Consensus Committee O behalf of the IHC. 2010 consensus statement on the worldwide standardization of the hemoglobin A1C measurement. Diabetes Care 2010, 33, 1903-1904. [CrossRef]

19. IBM Corp. IBM SPSS Statistics for Windows; Version 22.0; IBM Corp. n.d.: Armonk, NY, USA, 2013.

20. Ocón Bretón, M.J.; Ilundain González, A.I.; Altemir Trallero, J.; Agudo Tabuenca, A.; Gimeno Orna, J.A. Factores predictores de hipertrigliceridemia en pacientes hospitalizados con nutrición parenteral total. Nutr. Hosp. 2017, 34, 505-511. [CrossRef]

21. Badia-Tahull, M.B.; Llop-Talaveron, J.; Leiva-Badosa, E. Impact of intravenous lipid emulsions on liver function tests: Contribution of parenteral fish oil. Nutrition 2015, 31, 1109-1116. [CrossRef]

22. Llop-Talaveron, J.M.; Badia-Tahull, M.B.; Leiva-Badosa, E.; Ramon-Torrel, J.M. Parenteral fish oil and liver function tests in hospitalized adult patients receiving parenteral nutrition: A propensity score-matched analysis. Clin. Nutr. 2017, 36, 1082-1088. [CrossRef] [PubMed]

23. Zaloga, G.P. Phytosterols, Lipid Administration, and Liver Disease During Parenteral Nutrition. J. Parenter. Enter. Nutr. 2015, 39, 39S-60S. [CrossRef] [PubMed]

24. Llop-Talaveron, J.; Badía-Tahull, M.; Lozano-Andreu, T.; Rigo-Bonnin, R.; Virgili-Casas, N.; Farran-Teixidó, L.; Llop-Talaveron, J.; Badía-Tahull, M.; Lozano-Andreu, T.; Rigo-Bonnin, R.; et al. Phytosterolemia and $\gamma$-glutamyl transferase in adults with parenteral nutrition: Fish versus vegetal lipids: A randomized clinical trial. Nutrition 2020, 70. [CrossRef] 
25. Llop-Talaveron, J.M.; Leiva-Badosa, E.; Novak, A.; Rigo-Bonnin, R.; Tico-Grau, J.R.; Suñé-Negre, J.M.; Suárez-Lledó, A.; Lozano-Andreu, T.; Badía-Tahull, M.B. Phytosterolemia associated with parenteral nutrition administration in adult patients. Br. J. Nutr. 2020, 1-8. [CrossRef]

26. Madnawat, H.; Welu, A.L.; Gilbert, E.J.; Taylor, D.B.; Jain, S.; Manithody, C.; Madnawat, H.; Welu, A.L.; Gilbert, E.J.; Taylor, D.B.; et al. Mechanisms of Parenteral Nutrition-Associated Liver and Gut Injury. Nutr. Clin. Pract. 2020, 35, 63-71. [CrossRef] [PubMed]

27. Edmunds, C.E.; Brody, R.A.; Parrott, J.S.; Stankorb, S.M.; Heyland, D.K. The effects of different IV fat emulsions on clinical outcomes in critically ill patients. Crit. Care Med. 2014, 42, 1168-1177. [CrossRef]

28. Senkal, M.; Geier, B.; Hannemann, M.; Deska, T.; Linseisen, J.; Wolfram, G.; Adolph, M. Supplementation of $\Omega-3$ Fatty Acids in Parenteral Nutrition Beneficially Alters Phospholipid Fatty Acid Pattern. J. Parenter. Enter. Nutr. 2007, 31, 12-17. [CrossRef]

29. Mateu-De-Antonio, J.; Florit-Sureda, M. Efectos no relacionados con la antiinfl amación de las emulsiones lipídicas que contienen aceite de pescado en la nutrición parenteral para pacientes adultos. Nutr. Hosp. 2017, 34, 193-203. [CrossRef]

30. Olveira, G.; Abuín-Fernández, J.; López, R.; Herranz, S.; García-Almeida, J.M.; Argente-Pla, M.; Ferrer, M.; Moreno-Borreguero, A.; Luengo-Pérez, L.M.; Álvarez, J.; et al. Risk factors for hypoglycemia in inpatients with Total Parenteral Nutrition and Type 2 Diabetes: A post-hoc analysis of the INSUPAR study. Endocr. Pract. 2020. [CrossRef]

(C) 2020 by the authors. Licensee MDPI, Basel, Switzerland. This article is an open access article distributed under the terms and conditions of the Creative Commons Attribution (CC BY) license (http://creativecommons.org/licenses/by/4.0/). 